'post-traumatic' reactions? According to DSM-IV-TR criteria for post-traumatic stress disorder (PTSD) (American Psychiatric Association, 2001), a traumatic event requires that 'the person experienced, witnessed, or was confronted with an event or events that involved actual or threatened death or serious injury, or a threat to the physical integrity of self or others' (further requiring that 'others' must be persons, not animals) and that 'the person's response involved intense fear, helplessness, or horror' (p. 467). We seriously question livestock loss as a traumatic event.

Loosening criteria for a traumatic event represents a progressive 'conceptual bracket creep' in defining trauma (McNally, 2003). Will the next study examine PTSD in children 'traumatised' by their pet hamster's death, or from watching Bambi die in the famous Disney movie? What about being exposed to offensive remarks by others (Avina \& O'Donohue, 2002)? With the current trajectory all negative experiences will be synonymous with traumatic events, trivialising the experiences of real trauma victims. We ask where will researchers finally draw the line in what is considered traumatic? Continued disregard for the criteria will lead to anyone being considered traumaexposed and eligible for a PTSD diagnosis. With healthcare resource limitations, truly trauma-exposed and symptomatic patients could consequently be denied care (at a minimum subjected to extensive waiting lists), and our courts would be crippled with unnecessary PTSD litigation.

Olff et al (2005) claim that 'Although the foot and mouth crisis is not a traumatic event in the usual sense, the consequences do resemble features of PTSD' (p. 166). This statement minimises (without justifying) the authors' disregard for trauma criteria, and poses a circular argument in contending that the presence of PTSD symptoms confirms trauma exposure. However, trauma exposure must be distinguished from PTSD, since minor stressors (e.g. taking a nightshift job) can result in symptoms (e.g. difficulties in sleeping, problems concentrating) that are aetiologically distinct from PTSD.

American Psychiatric Association (200I) Diagnostic and Statistical Manual of Mental Disorders (4th edn, revised) (DSM-IV-TR). Washington, DC: APA.

Avina, C. \& O'Donohue, W. (2002) Sexual harassment and PTSD: is sexual harassment diagnosable trauma? journal of Traumatic Stress, 15, 69-75.
McNally, R. J. (2003) Progress and controversy in the study of posttraumatic stress disorder. Annual Review of Psychology, 54, 229-252.

Olff, M., Koeter, M. W. J., Van Haaften, E. H., et al (2005) Impact of a foot and mouth disease crisis on post-traumatic stress symptoms in farmers. British Journal of Psychiatry, 186, 165-166.

J. D. Elhai Disaster Mental Health Institute, The University of South Dakota, 414 East Clark Street SDU II4, Vermillion, South Dakota, USA. E-mail: jelhai@usd.edu

T. B. Kashdan Department of Psychology, George Mason University, Fairfax, Virginia, USA

B. C. Frueh Charleston Veterans Affairs Medical Center and Department of Psychiatry and Behavioral Sciences, Medical University of South Carolina, Charleston, South Carolina, USA

Authors' reply: Post-traumatic stress disorder is unusual among DSM disorders in that the diagnostic criteria specify an aetiological event: exposure to a traumatic stressor. In their letter Elhai et al cite examples that do not meet the stressor criterion, the symptom criteria for PTSD, or the criteria of distress or impairment. The DSM-IV symptoms (re-experiencing, avoidance/ numbing and hyperarousal) are defined in terms of their connection with a traumatic event. The 'conceptual bracket creep' (McNally, 2003) refers to the broadening of the stressor criterion in DSM-IV, especially to the inclusion of 'second-hand exposure', such as learning about the unexpected death of a close friend/relative or watching atrocities on television (see Rosenbaum, 2004). This seems to increase the eligible events by about $20 \%$ (Breslau $\&$ Kessler, 2001). However, more important is the question addressed in the DSMIV guidebook 'whether or not to include reactions to the numerous stressors that are upsetting, but not life threatening (Frances et al, 1995: p. 259) or even to eliminate the stressor criterion altogether. The fear that more inclusive definitions will vastly increase the frequency of the diagnosis seems to be unrealistic. More minor stressors simply will not result in the other diagnostic criteria for PTSD.

McNally (2003) makes an important point in stating that with the inclusion of such diverse events it will be difficult to identify common psychobiological mechanisms underlying symptomatic expression. In our opinion, to develop PTSD the stressor - often associated with severe sadness - should be intense enough to evoke a psychobiological dysregulation of the fear system, which results in the event being re-experienced, avoided and leading to a state of hyperarousal where the person feels that danger could strike again at any moment. This psychobiological stress response is dependent on subjective appraisal of the event and not on objective criteria of stressor severity (Olff $e t$ al, 2005). This would suggest that 'second-hand exposure', non-typical traumatic stressors or even life events might in some instances evoke an intense psychobiological dysregulation leading to 'PTSD' symptoms. Apparently, this was the case for the farmers who witnessed (saw, heard, smelled) all their animals being destroyed, an event that was beyond their control and is certainly 'outside the range of their normal experience'.

Mental healthcare should be available to those with significant mental health problems, even if these are considered subthreshold for PTSD. By conducting a large epidemiological survey in The Netherlands we hope to determine what kind of stressors (including life events) evoke what kind of 'post-traumatic' symptoms, as well as the implications for mental healthcare.

Breslau, N. \& Kessler, R. C. (200I) The stressor criterion in DSM-IV posttraumatic stress disorder, an empirical investigation. Biological Psychiatry, 50, 699-704.

Frances, A., First, M. B. \& Pincus, H. A. (1995) DSM-IV Guidebook. Washington, DC: American Psychiatric Press.

McNally, R. J. (2003) Progress and controversy in the study of posttraumatic stress disorder. Annual Review of Psychology, 54, 229-252.

Olff, M., Langeland, W. \& Gersons, B. P. R. (2005)

Effects of appraisal and coping on the neuroendocrine response to extreme stress. Neuroscience and Biobehavioral Reviews, 29, 457-467.

Rosenbaum, L. (2004) Post-traumatic stress disorder: the chameleon of psychiatry. Nordic Journal of Psychiatry, 58, 343-348.

M. Olff, B. Gersons Centre for Psychotrauma, Academic Medical Centre/De Meren, Department of Psychiatry, University of Amsterdam, Tafelbergweg 25, II05 BC Amsterdam, The Netherlands. E-mail: m.olff@amc.uva.n

\section{Potentially preventable suicide}

We read the short report by Bennewith et al (2005) with interest. The authors attempted to address one of the objectives of the National Suicide Prevention Strategy for England, restricting access to means of suicide (Department of Health, 2002).

The authors found 10 cases $(6 \%)$ of 'potentially preventable' suicide by hanging in controlled environments such as hospitals and prisons, among 162 cases of a 
randomly selected sample of suicide by hanging from a wide geographical area in England.

We would like to make the following comments. The report made no reference to the proportion of older victims in the randomly selected sample. The mean age given in the report (41 years) is almost the same as that for all people over the age of 16 years in England and Wales who hanged themselves in the same year as the study (2001) and over the past 23 years. These cases include, on average, $16 \%$ over the age of 64 years. This means that the study sample of 162 contained at least 25 victims over the age of 64 , a sizeable older element that was not referred to in the report.

This is important and ought to have been clarified particularly in relation to the deaths that occurred in hospital when the victims were found seated $(4.7 \%)$, kneeling $(7.4 \%)$, lying $(8.7 \%)$ or partially suspended $(3.4 \%)$ and to individuals who were found alive $(4.3 \%)$. However, this does not apply to hanging in prison where victims had an estimated mean age of 28 years (Shaw et al, 2004).

We calculate the expected annual rate of 'potentially preventable suicides by hanging' within institutions (controlled environment) in England and Wales to be about 110 cases of a total of 1300 expected annual suicides by hanging: 86 in prison (Shaw et al, 2004) and 24 (about a third of 71 hanging incidents by psychiatric inpatients) in hospital (Department of Health, 1999). 'Potentially preventable suicide by hanging' in controlled environments involving prisoners represents $5 \%$ of all suicide by hanging in England and Wales and $2 \%$ in the case of psychiatric in-patients. This is remarkably similar to the $6 \%$ in the report of Bennewith et al.

It would be of real interest, and certainly of practical value, if future studies specifically investigated suicide by hanging within controlled environments such as hospitals and prisons using an appropriately selected sample over a period of time (e.g. 220 incidents expected over 2 years in England and Wales, based on current figures). This would provide a study with acceptable power and some inferential value compared with the modest 10 cases reported by Bennewith et al.

Bennewith, O., Gunnell, D., Kapur, N., et al (2005) Suicide by hanging: multicentre study based on coroners' records in England. British Journal of Psychiatry, 186, 260-26I.
Department of Health (1999) National Confidential Inquiry Into Suicide and Homicide by People with Mental Health Problems, pp. 38-39. London: Department of Health.

Department of Health (2002) National Suicide Prevention Strategy for England. London: Department of Health.

Shaw, J., Baker, D., Hunt, I. M., et al (2004) Suicide by prisoners: national clinical survey. British Journal of Psychiatry, 184, 263-267.

E. Salib, M.Theophanous Peasley Cross Hospital, St Helens, 5 Boroughs Partnership Trust, Hollins Park, Winwick, Warrington WA2 8WA, UK. E-mail: esalib@hotmail.com

Authors' reply: The aim of our research was to undertake a detailed assessment of a sample of all (community and institutional) suicides by hanging in a defined geographical area over a 6-month period, focusing on potentially preventable aspects of these deaths. The context for the research was the rise in suicides by hanging in England and Wales (Gunnell et al, 2005) and the National Suicide Prevention Strategy for England (Department of Health, 2002). Of note, rates of suicide by hanging have not increased among men or women aged 65 years and over (Gunnell et al, 2005). Although generally Office for National Statistics figures for England and Wales from the 1970s onwards show that rates per 100000 for deaths by hanging were higher in those aged 65 and over compared with rates in other age groups, this is not the case from 2000 onward when rates for death by hanging increased in the 15- to 44-year age group and decreased among those aged 65 and over (Gunnell et al, 2005).

The Editor decided that our paper should be resubmitted as a short report. The limited space did not enable us to give a full breakdown of the distribution of age, gender, race, social class, etc. of all of our sample. In response to the concern of Drs Salib and Theophanous we can confirm that $13(8.0 \%)$ of the 162 cases in our study were aged over 65 years. Furthermore, 19 $(11.7 \%)$ were aged under 25 years and $139(85.8 \%)$ were male.

For those interested in a more detailed account of suicides in psychiatric hospitals and prisons we suggest the following sources: Dooley (1990), Shaw et al (2003), Shaw et al (2004) and Gunnell et al (2005).
Department of Health (2002) National Suicide Prevention Strategy for England. London: Department of Health.

Dooley, E. (1990) Prison suicide in England and Wales 1972-87. British Journal of Psychiatry, 156, 40-45.

Gunnell, D., Bennewith, O., Hawton, K., et al (2005) The epidemiology and management of suicide by hanging: a review. International Journal of Epidemiology, 34, 433-442.

Shaw, J., Appleby, L. \& Baker, D. (2003) Safer Prisons: A National Study of Prison Suicides 1999-2000 by the National Confidential Inquiry into Suicides and Homicides by People with Mental IIIness. London: Department of Health.

Shaw, J., Baker, D., Hunt, I. M., et al (2004) Suicide by prisoners: National clinical survey. British Journal of Psychiatry, 184, 263-267.

O. Bennewith, D. Gunnell Department of Social Medicine, University of Bristol, Bristol BS8 2PR, UK

N. Kapur, P.Turnbull Department of Psychiatry and Behavioural Sciences, Manchester Royal Infirmary, Manchester

S. Simkin, L. Sutton, K. Hawton Centre for Suicide Research, University Department of Psychiatry,Warneford Hospital, Oxford

\section{Transcranial direct current stimulation in developing countries}

The suggestion by Fregni et al (2005) that transcranial direct current stimulation (tDCS) might be an inexpensive solution to the lack of resources for the treatment of depression in developing countries is well meaning but does not take into account the real reasons for the poor uptake of psychiatric treatments. If, as the authors state, the uptake is only $34 \%$ in a resource-rich country such as the USA with its high educational levels and awareness campaigns, a rate of $17 \%$ in Brazil is not surprising and is most likely not due to the lack of affordable drugs (Chisholm et al, 2004). Cheap and effective, if not the latest, antidepressant drugs are usually available in most countries. In making their suggestion, the authors also ignore the expert opinion regarding the first-line management of depression around the world (Crawford, 2004). Most commentators would agree that this should be pharmacotherapy and not direct magnetic or electrical stimulation of the brain. The lack of primary healthcare facilities in many countries makes the suggestion of tDCS as a primary intervention impractical.

My major concern, however, is not that the authors recommend $\mathrm{tDCS}$ as a first-line intervention but that they recommend it as an intervention at all. By basing their 